\section{NEW APPRENTICESHIP IN PRACTICE MANAGEMENT}

A brand new Apprenticeship in Dental Practice Management will give young people a fantastic opportunity to become the senior managers of the future.

Developed under phase 2 of the government's Trailblazer projects, the Apprenticeship will provide young people with the necessary knowledge, skills and experience to progress up the career ladder.

Over 24 months, apprentices will learn to manage all non-clinical aspects within a specified practice or practices. On completion, they will attain a certificate in Dental Practice Management and may be fast tracked through to achieve a diploma in Dental Business Management or an MSc/MBA in the Business of Dentistry.

Companies offering the apprenticeships can look forward to increasing productivity and performance by developing a team of motivated, enthusiastic and highly skilled employees.

Recently appointed as Chair of the Dental Trailblazer sector, Mustafa Mohammed, owner and founder of Genix Healthcare and Sparkle Dental Labs, continues to work alongside the Government to develop these exciting apprenticeships to offer an array of advantages for employees, employers, the UK dental industry and economy.

Find out today how the new Dental Practice Management Apprenticeship could transform your business. For additional information, visit the website: www. apprenticeship.org.uk.

\section{NEW HOME FOR SPECIALIST IMAGING}

Cavendish Imaging has moved its flagship stateof-the-art specialist medical imaging facility to dedicated premises at 109 Harley Street.

The independent centre of excellence is equipped with the latest technology to provide high quality cone beam CT scans, 3D photographs and anatomical modelling and has a wealth of expertise available on site, including IT support and laboratory services.

Over the past six years, Cavendish Imaging has purchased three Morita 3D Accuitomo 170 cone beam CT scanners for sites in London and Birmingham.

The new centre is focused on imaging of the head and neck and limbs. The team are able to provide improved results, with low X-ray dose, and increased speed and efficiency.
The modelling facility uses the latest technology to produce high resolution, rapid prototype models from any scan data, in as little as 24 hours. These are offered to surgeons working all over the UK and internationally, in any speciality.

The London branch has a 'walkin' option for most examinations, with results available immediately. The company also has cone beam CT scanning facilities at centres in Birmingham, Nottingham and Oxford.

For further information call 08453883380 or email info@ morita-uk.com.

\title{
MAKING VISUALLY PERFECT RESULTS POSSIBLE
}

Bifix Temp combines highest aesthetics and simplest applicability and thus now makes visually perfect results possible for temporary restorations. The translucent and tooth-like shade universal ideally adapts to highly aesthetic temporaries, does not shine through and promotes the natural appearance of the temporary treatment. Thanks to film layers of below $5 \mu \mathrm{m}$ in thickness temporaries can be luted to fit perfectly and without requiring time-consuming finishing work.

Dual-curing is facilitated by the fact that the material is compositebased. The material can be worked for approximately 90 seconds and self-cures within four minutes. Use of a polymerisation light can shorten the setting time, thus giving the dentist flexibility. For removal of excess material, the so-called 'tack cure' technique can be used here, meaning that any surplus material can easily be removed in one piece by brief exposure to the curing light, which causes them to become elastic. Any potential residues are very easy to find and remove as their universal shade stands out very well against the gingiva.

The proven QuickMix syringe with mixing tip type 9 makes the application of Bifix Temp very easy, as the components are automatically mixed in the process of extraction. Thus errors relating to dosage and mixing, as those which may occur during manual mixing, are prevented. The short tip results in a low level of material loss, meaning that more applications are possible per syringe in comparison with similar competitive products.

www.voco.com. Special offer: buy 2 get 1 free. Contact your VOCO dental consultant!
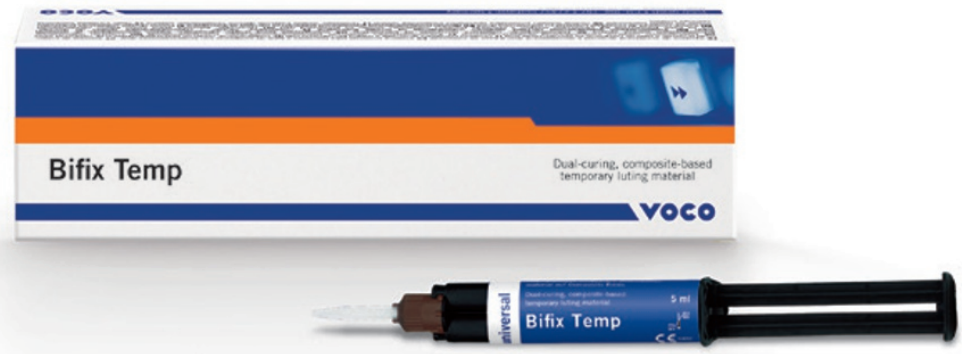

\section{GAIN CONFIDENCE QUICKLY}

CEREC is fast becoming the first choice for all ceramic restorations in dental practices throughout the UK.

With many years of experience Sirona Dental Systems achieves an even higher level of training CEREC users of all levels, whether you are an experienced CEREC user or someone who has just taken delivery of their CEREC for the first time. Sirona's training is designed to ensure new users quickly gain confidence whilst those more experienced users look to carry out more complicated cases.

To find out and understand the CEREC CAD/CAM technology, why not contact a member of the Sirona team and book your place on the next available date to sample just how easy CEREC really is to use.

CEREC courses take place at
Sirona's Centre of Excellence close to Heathrow Airport with excellent road and rail links. Numbers on these CPD accredited courses are restricted so please book early to avoid disappointment. To reserve your place or further information please contact Sirona UK directly on 08450715040. 